\title{
MOTIVACIONES PARA EL ESTUDIO DEL ESPAÑOL EN LAS GRAMATICAS DEL SIGLO XVI
}

¿Puede hablarse hoy, como en el siglo XvI, de la necesidad de conocer, como segunda lengua, el español? Mucho me temo que la respuesta, desde perspectivas europeas, sea desgraciadamente negativa. La pregunta, planteada teóricamente, tiene una contestación obvia; pero en el campo pragmático el tablero de intereses apunta hacia otros derroteros. Es mi intención, en las páginas que siguen, mostrar las justificaciones que aparecen en las gramáticas, tendentes a suscitar en los lectores extranjeros la necesidad de conocer la lengua española; pero también la acción política hispana, en esa época, incide en las vicisitudes por las que muchas veces pasa el español dentro de los manuales europeos de la época. Sin pretensiones de exhaustividad presentaré primero algunos casos de la correlación política -aparición/desaparición del español一, para luego detenerme en las motivaciones que se esgrimen para el conocimiento de nuestra lengua.

\section{LA POLf́frCA}

En el siglo xvi es posible vincular la aparición de una Gramática o de un Vocabulario políglota, etc. a situaciones políticas concretas, unas veces explícitamente confesadas, otras no, pero que debieron responder a actitudes en ese momento transparentes, aunque para nosotros permanezcan hoy veladas. Podría hablarse de una glotopolítica, igual que se habla de una geopolítica.

Presentaré algunos ejemplos, sin que pueda afirmarse para todos una relación causal clara y manifiesta; pero, en mi opinión, el contexto histórico aducido arroja un poco de luz aunque el hecho. politico concreto, fechado, sea en muchos casos simplemente indicativo. 
Comenzaré por un caso ya conocido pues fue ampliamente tratado por A. Alonso: Las Reglas Gramaticales de Antonio Corro ${ }^{1}$. La acción política religiosa llevada a cabo en el convento jerónimo de San Isidoro del Campo en Sevilla, donde se había descubierto un importante foco calvinista, determina la huida de Corro. Es en la corte calvinista de los Albret de Bearne donde, como educadores del futuro Enrique IV, se reúnen reformistas tales como La Gaucherie (jefe de los maestros), Théodore Bèze (teólogo y filólogo) y el sevillano Corro especialmente recomendado por Calvino; y en Nérac "cuando enseñaba el lenguaje Español al Rey Don Henrique de Navarra", escribe Corro las Reglas Gramaticales que luego se publicarian en Oxford en I586 (para aprender español y francés) y servirían en 1590 integramente para su Spanish Grammar (ésta para enseñar español a los ingleses). Sin esas circunstancias religiosas, Corro no habría escrito una gramática; lo hizo, como señala A. Alonso "para tener él mismo un instrumento de enseñanza»"

Mayor interés tiene desde el punto de vista político el caso de los Vocabularios políglotas, derivados del de Noel de Berlaimont, estudiados por Verdeyen, Riemens y Bourland ${ }^{3}$. Mi atención se centrará en las sustituciones o adiciones de un idioma por otro y trataré de dar alguna explicación plausible a partir de ciertos hechos históricos, en vez de quedarme, como los autores citados, en la simple constatación del hecho de la sustitución/adición.

Es sabido que el español aparece en los Vocabularios políglotas de modo casi persistente 4; una estimación aproximada hecha por Bourland ${ }^{5}$ sobre la relación dada por Verdeyen, ofrece los siguientes datos: de 77 vocabularios el castellano está presente al menos en 60; y de las

1 A. Alonso, Identificación de gramáticos españoles, en $R F E \mathrm{XXXV}, 195 \mathrm{I}$, pp. 226-236.

- A. Alonso, Art. cit., p. 235.

8 R. VERDEVF, Colloquia et Dictionariolum septem linguarum, t. I., Amberes, 1926 (Uitgave van de vereeniging der Aantwerpsche bibliophilen, núm. 39) y t. II, I925 (Litgave van de vereeniging... ním. .40); hay ejemplares en la Biblioteca Nacional de Madrid; K. J. RIEMENS, Bi,drage tot de Bibliografie van Nöel van Berlaimont, citado por C. B. Bourland; C. B. BourI,AND, The Spanish SchooleMaster and the Polyglot Derivatives of Noel de Berlaimont's Vocabulare, en RHi. IXXXI, I933, pp. 283-318.

- Sólo el francés permanece en todos, cosa lógica dado el origen del Vocabulave que, como sugiero más adelante, pudo surgir para resolver el entendimiento lingiístico entre las \%onas flamenca y valona.

b Art. cit., p. 300. 
adiciones que esta autora hizo a dicho Catálogo ${ }^{1}$ está en todos menos en uno. Se trata de la ed. de $\mathrm{I}_{585}$ hecha por Jakobszoon y Bouwenszoon en Leyden, Colloqves, Ov Dialogves, Avec Vn Dictionaire en quattre langues: Flamen, Anglois, François \& Latin. Resulta sorprendente la supresión del español, máxime tratándose de un vocabulario tetralingüe. ¿Cómo justificarlo y cómo interpretar la sustitución por el inglés? Si tenemos en cuenta la fecha y el lugar de edición, los acontecimientos politicos y militares esclarecen en parte estos hechos satisfactoriamente. Es un momento en que Holanda se debate en una fuerte crisis económica. Su estatúder, Guillermo de Orange, fue asesinado en I584; en campañas estratégicamente planeadas, el gobernador de los Países Bajos - Alejandro Farnesio- ha aplastado la rebelión y la caída de Amberes, en I585, corona su acción bélica. La situación para Holanda parecía virtualmente perdida cuando Isabel I de Inglaterra interviene activamente enviando un ejército al mando del Conde de Leicester; si hasta entonces los británicos, aunque favorables a los holandeses, no se habían querido comprometer demasiado, esta decisión de ${ }^{585}$ tomada ante el temor de que los españoles, sin enemigos en los Países Bajos, tuvieran acceso directo a las costas inglesas, derivó el conflicto hacia un nuevo escenario: la lucha por el océano que culminaria con la guerra a muerte de ${ }^{5} 88$ y el desastre de la Invencible ${ }^{2}$.

En este contexto la desaparición de la versión castellana y la inclusión de la inglesa en los Colloques de ${ }^{585}$ encuentran justificación: una hispanofobia creciente que llega a sus mayores cotas por estas fechas; la desaparición del castellano es como una simbólica manifestación (la única que en esos momentos se podía) del espiritu nacionalista holandés; la sustitución del español por el inglés sellaba, también simbólicamente, el reconocimiento a la ayuda solapada que Inglaterra ofrecia desde I572 a los mendigos del mar, los corsarios holandeses que gracias a la acogida en puertos británicos operaban en el mar del Norte.

También podríamos encontrar en los acontecimientos dramáticos de 1572 la explicación del porqué inglés y alemán son las dos primeras lenguas que se incorporan a los vocabularios tetralingües para convertirlos en hexalingües. El primero de éstos es de 1576, impreso en Amberes por Henricum Henricium (Heyndricx) ${ }^{3}$. La insurrección holandesa

1 Art. cit., pp. 3I3-3I7; son en total II ediciones que van desde $155^{8}$ a 1677 .

- Cf. J. I. CoMELl.AS, Historia de España Moderna y Contempordnea. Madrid, 1974, t. I, pp. .404 y ss.

- Colloques ou Dialogues avec un Dictionaire en six langues. Cf. Bourland, art. cit., pp. $297-298$. 
del 72 se había extendido rápidamente por todos los Países Bajos con un innegable trasfondo nacionalista popular; desde la toma de Brielle (I572), la mayor parte de la población ayudó a los mendigos del mar y sobre todo la ayuda de Guillermo de Orange con su ejército mercenario de alemanes (se calcula que había reclutado más de 20.000) y la de su hermano Luis de Nassau, quien con los hugonotes había armado el ejército más fuerte y mejor organizado. El nuevo Gobernador de los Países Bajos, Luis de Requeséns, cuando muere en 1576 no había conseguido apaciguar el país flamenco: la intransigencia de Orange hizo inviable la conferencia de Breda y el perdón general, redactado en I574, pareció debilidad. El hecho es que en la conflictiva Holanda los españoles no eran dueños más que de las posiciones que pisaban; las tropas alemanas continuaban; los mismos tercios españoles, hambrientos, descontrolados, habían asaltado la ciudad de Amberes dejando un triste recuerdo de la furia española (I576). En esa caótica situación casi se preveía la desvinculación del Archiducado de la Corona Española, como lo demuestra el hecho de que a la llegada de D. Juan de Austria (I577), pese a que aceptó el Edicto Perpetuo (restauración de todos los viejos privilegios, alejamiento de tropas y gobernantes extranjeros, administración con personal y recursos propios, etc.), Holanda y Zelanda rechazaron la autoridad del hermano de Felipe II. El mismo Orange se establece en Bruselas (I577) impunemente, e incluso el Archiduque Matias pretende ser reconocido como Gobernador, alegando que los Países Bajos debieran estar vinculados al Imperio Alemán como en tiempos de Maximiliano.

En resumen: la presencia de tropas alemanas y la ayuda inglesa de los mendigos del mar justifican la incorporación del inglés y alemán al vocabulario de Heyndricx.

Hay que vincular también a un hecho político la labor difusora del español de un impresor de Lovaina; Bartolomé Gravio, que coincide con la etapa política de Carlos $\mathrm{V}$ que los historiadores califican de germano-flamenca (I544-I556). Puede conjeturarse que la probada ortodoxia de Gravio debió influir en su nombramiento como «impresor jurado", es decir "oficial», "bajo juramento», del Colegio Trilingüe de Lovaina. La estima con que contaba Gravio en medios eclesiásticos por la impresión de obras de carácter teológico debió ser grande; el agustino jerezano, Lorenzo de Villavicencio (maestro eminente en teología y oratoria sagrada, según atestigua Nicolás Antonio) dedicó altos elogios a Gravio por su edición de la Biblia, justamente en una época en que la impresión de libros religiosos - fundamentalmente la Bibliadesligados de la ortodoxia romana fue grande; no es extraño que el 
agustino alabe «la fe, sinceridad y diligencia» de este "librero y tipógrafo de la Ilustrísima y Cristianísima escuela de Lovaina» ${ }^{1}$.

No existió en los Países Bajos otra oficina, otra imprenta, que, ella sola, editara tantas obras lingüísticas. En I55I la primera versión del Vocabulare de Noel de Berlaimont; 1555, la Vtil y Breve Institvtion para aprender los principios y fundamentos de la Lengua Hespañola; I555, la Grammatica Volgare de M. Alberto de Gl'Acharisi Dacento (en italiano y francés); 1556 , la segunda edición del Vocabulario; en $155^{8}$ 1a tercera; 1559, la Gramatica de la Lengua Vulgar de España, y 1560 la cuarta edición del Vocabulario. No es este el momento de analizar esta labor editora; por otra parte Bourland se ha referido con cierta extensión a los Vocabularios políglotas desde un punto de vista descriptivo; A. Alonso ha utilizado los datos suministrados por las ediciones de Gravio en sus estudios sobre la pronunciación de la época; yo mismo he estudiado las dos gramáticas: la de I555 (recientemente publicada) y la de 1559 . Pero quedan aún muchos problemas pendientes, no siendo el menos importante el establecimiento de las fuentes en un panorama que establezca los débitos y créditos de los distintos manuales. Porque el concepto de plagio no puede ser en el siglo XvI, enjuiciado desde nuestra perspectiva actual. Casi desdeñosamente A. Alonso consideró la labor de Gravio como "material industrial»; como fuente principal para el Anónimo de 1559 citaba a Meurier; es cierto que las Coniugaisons y la Breve instruction contenante la maniere de bien prononcer \& lire le François, Italien, Español \& Flamen (Amberes, Waesberghe, I558), pasaron (íntegras o modificadas) a la mayoría de los manuales del Xvi (Saleson, I568; Bellere, 1569; Sotomayor, 1565; Heyndricx, I576, etc.); pero también es cierto que Meurier se aprovecha liberalmente del Vocabulare de Noel de Berlaimont y casi más seguro de los próximos descendientes, entre ellos los de Gravio, cuya obra, como he señalado en el estudio del Anónimo de I555 fue también objeto de plagios.

Un último ejemplo de cómo un hecho político determina la aparición de una obra, a propósito de Meurier. ¿En qué contexto histórico aparece la obra de Meurier? Precisamente cuando en I557 se ha obtenido el resonante triunfo de San Quintín, mientras que Guisa en Italia, neutralizado por el Duque de Alba, regresa a Francia derrotado y sin

1 De Recte ! Formando Theolo- / giae studio, Libri quator: Restituti / per Fratrem Laurentium i Villauice- / tio Xerezanum, Doitorem Theo- $i$ log. Agustinianum E- / remitam [escudu] Antverpiae..., r5658; ejemplar en la Biblioteca Nacional de Madrid, R 31653. 
haber librado una sola batalla; cuando en ${ }_{5} 55^{8}$ la ofensiva francesa es anulada en Gravelinas mediante una acción conjunta de tierra y mar con la flota anglo-española (Felipe II está casado con María Tudor), y cuando un hecho inesperado - la muerte de ésta - desvincula a Felipe II de la corona inglesa y por razones de prudencia (se ignora el rumbo político de Isabel de Inglaterra), el soberano se casa con Isabel de Valois, y como colofón la paz de Cateau-Cambrésis (I559). Meurier pone un prólogo que luego en $\mathrm{I}_{565}$ copiaría Sotomayor: el francés es necesario "con el felicissimo matrimonio de la reyna nuestra señora» ${ }^{\text {. }}$

\section{LAS MOTIVACIONES}

He aducido algunas muestras de interpretación glotopolítica. Es ahora el propósito de mi intención mostrar, también en un panorama selectivo de textos, las motivaciones que se esgrimen en las Gramáticas, Diccionarios y Vocabularios del siglo XVI, tendentes a justificar la necesidad de que la lengua española sea conocida en amplias capas sociales que abarcan desde el estudiante hasta el mercader, desde la corte hasta la milicia, desde el docto erudito hasta el viajero ávido de conocer experimentalmente el hecho de que su país termina en unas coordenadas geográficas. Aunque los textos podrían ampliarse me limitaré a los imprescindibles. Agrupo en seis apartados las motivaciones aducidas por autores y editores; a partir de estas justificaciones - y cuando proceda - enlazo con determinados problemas de orden técnico o histórico; es evidente que alguno de estos grupos que hago tienen una interpretación política, pero rebasan su justificación desde un hecho concreto, como ocurría en los ejemplos anteriormente expuestos. E, orden en que los propongo no supone una jerarquización absoluta en importancia, si bien hay una relativa y progresiva profundización esencial; por otra parte la interconexión de algunos es tan estrecha que bien podría hablarse de relaciones causativas.

1 Grammatica / con reglas mvy pro- / uechosas y necessarias para apren- / dev a leer y escriuir la lengua Francesa, / conferida con la Castellana, con / vn vocabulario copioso de / las mesmas lenguas. / Dirigido a los muy Illusires señores / Corregidor y Toledo [escudo]. Con Previlegio Real. / Impressa en Alcala de Henares en casa de / Pedro de Robles, y Francisco de Cormellas / Vendense en casa de I uan de Escobedo / Librevo en corte. Año de / 1565 . Ejemplar en la Biblioteca Nacional de Madrid, R 9599. 


\section{A) La moda}

El primer argumento que vamos a ver, está en íntima relación con el fenómeno sociológico de la moda, fenómeno de todas las épocas, bien a niveles internacionales o dentro del ámbito de una comunidad en sus diversos estratos sociales. En la comunicación supranacional las relaciones económicas juegan un papel importante a la hora de generalizar la tendencia por la posesión de una segunda lengua. Pero también la elección arranca muchas veces de complejas situaciones sicológicas (afinidades ideológicas, culturales o simplemente imitativas de la actitud de una clase superior socialmente).

Una segunda lengua puede ser promocionada por una clase social elevada, como signo de diferenciación que marca un mundo cerrado, inaccesible; los ejemplos históricos son harto conocidos. La lengua se prestigia de ordinario en la Corte y altos estamentos administrativos, y ello puede obedecer a dos razones fundamentales: el propio entorno de la corte o motivaciones que deben insertarse en un fenómeno cultural (se sigue la opinión de los ingenios $\mathrm{y}$ aficionados al saber).

La primera razón -entorno cortesano - que determina la preferencia por una segunda lengua es, en su raíz, un hecho polf́tico.

Sotomayor (1565) en un plagio a Meurier, adaptado, nos dice: "quien de aqui adelante no supiere Frances, le faltara mucha parte de la $\bar{q}$ el buen cortesano deue tener; pues vno de los mayores entretenimientos $\bar{q}$ entre ellos ay es el trato que con las damas se tiene, de las quales muchas son francesas» (f. A r. y v.). Se trata de la corte de Isabel de la Paz.

E1 entorno de la corte de Bruselas es, obviamente, de corte hispánico y eso explica que sea el español la primera lengua moderna que se incorpora a los Vocabularios poliglotas derivados del de Noel de Berlaimont.

E1 que sea el francés enseñado en Inglaterra antes que el español (1530, Eclaircissement de la langue Françoise, de Palsgrave) obedece a la alianza anglo-francesa frente a España; no hay vestigios de la preferencia por el español ni siquiera en el período de 1553-58 en que Felipe II es rey consorte de Inglaterra; tardará aún bastantes años y a ella habremos de referirnos luego.

La segunda razón señalada por la que las lenguas extranjeras se ponen de moda, responde, decía, a un fenómeno cultural, y debe encuadrarse en el marco del enriquecimiento que supone la posesión de otras 
lenguas. En 1570 el sevillano Christoval de las Casas ${ }^{1}$ afirma en la dedicatoria de su Vocabulario de las dos lenguas Toscana y Castellana: «los hombres bien aficionados, y amigos del saber, han pretendido el conocimiento de las lenguas estrangeras, para gozar de las riquezas de'llas, y trasladarla a nuestra nacion" (f. A. v.). Stepney, en I59I, recomienda "el conocimiento de muchos idiomas" ${ }^{2}$.

Quizás en este orden de cosas haya que destacarse la preferencia del italiano en cortes como la inglesa, alejadas de la política mediterránea; incluso en países como España, con constantes intereses políticos en Italia, el conocimiento del italiano responde a razones de tipo cultural y humanístico; el citado Christoval de las Casas señala que es tanta la curiosidad y diligencia de los humanistas italianos «en adornar y ennoblecer su tierra con todo genero de buenas letras, que no han dexado en Griego, ni en otras lenguas cosas, que no han passado ya à la suya... de manera que los que carescen de otras lenguas podran con solo esta, valerse bien para gozar largamente de todas las facultades que en ella hallaran" (f. Aj. r.).

La aceptación del castellano entre los cortesanos ingleses será tardía; Stepney la ve como un hecho futuro pero necesario: «No dudo que en tiempos venideros la lengua española será tan estimada como la francesa y la italiana» ${ }^{3}$; pero posiblemente por la tensa situación politica hay todavía en Stepney veladas reticencias para no tomar partido decidido por el español: «no querria que supusieras que deseo magnificar la singularidad de la lengua española sobre todas las otras lenguas” ${ }^{\mathbf{5}}$. Sin embargo, la utilidad del español sobre el italiano, matizada la expre-

1 Vocabvlario / de las dos lengvas Tosca- / na y castellana de Chris- / tobal de las Casas. / En que se contiene la declava/ción de Toscano en castellano y de castellano / en Toscano. En dos partes. / Con una introdvción para leer, / y pronunciar bien entrambas lenguas... / En Sevilla. 1570. Ejemplar en la P. N. de Madrid.

2 "albeit I would not haue you suppose, that I do magnifie the singularitie of the Spanish tongue...: but generally I do commend the knowledge in many tongues" (f. Aiij v.). The Spanish / Schoole-master. / Containeng seven / Dialogues according to euen day in the weeke... Newly collected and set forth by $W$. Stepncy, professor of / the said tongue in the famous Citie of London... I591. Biblioteca Nacional de Madrid, $\mathrm{R}$ I 3079 .

s Idem., f. Aiij v. Mientras no señale lo contrario las citas de Stepney pertenecen a la Epistle to the Reader.

- Bourland, art. cit., p. 301 , opina por cierto pasaje del $5 .^{\circ}$ Diálogo, que el libro se estaba escribiendo antes de 1588 , desastre de la Invencible; sin embargo, y en mi opinión, el citado pasaje podría también referirse a la derrota naval inglesa de I59I, a la altura de las Azores donde los españoles apresaron el Revenge.

- STEPNEY, idem., f. Aiij $\nabla$. 
sión con un protocolario en mi humilde opinión, es señalada sin ambages; y es lógico, porque Francia y los Países Bajos suponían una amenaza para Inglaterra, en tanto Italia quedaba alejada del área de su política; por ello afirmará: la lengua española «es mucho más necesaria para nuestros paisanos que la lengua italiana» ${ }^{1}$.

Como he indicado la entrada del castellano en Inglaterra es tardía; la preferencia por el francés e italiano ( $\mathrm{y}$ el hecho ha sido ya señalado por D. Alonso, Luis Cardim, Bourland) ${ }^{2}$, es anterior; recuérdese que en 1586 se publican las Reglas Gramaticales para aprender la lengua Española y Francesa... de Antonio del Corro; como ya demostró A. Alonso, este texto es el que se traduce al inglés (desaparece lógicamente la versión francesa) en $159^{\circ}$ y aparece como la Spanish Grammar, considerado como el primer texto para aprender español. Sin embargo, en mi opinión, debe considerarse a Stepney como quien de modo práctico introduce la enseñanza del castellano, pues él realiza mediante la inclusión de los Diálogos lo que constituye el fin de la gramática: la sintaxis (la originalidad y la corrección idiomática de estos Diálogos es un problema diferente). Antonio de Corro había ofrecido una Gramática y un Diccionario; Richard Percyvall, Bibliotheca Hispanica, I59I, sólo incluía la Gramática y un Diccionario inglés-español-latín; Stepney, en cambio, ofrece las reglas de pronunciación, sentencias, proverbios, oraciones, etc. y siete diálogos para cada día de la semana. No engañaba, pues, cuando afirmaba: "quise... atreuerme hazer y componer este Dialogo [el único original es el $7 .^{\circ}$ ] para introduction a la Iẽgua Castillana, a la qual bien se que v. s. es muy afficionado, tambien como a las otras lenguas" ${ }^{3}$; y se ajustaba a la realidad cuando en el título de la obra indicaba que estaba dirigida a quienes deseaban aprender español "dentro de nuestro reino de Inglaterra»"; fuera de Inglaterra, cualquier inglés podía introducirse en el conocimiento del español utilizando la obra de Heyndricx, hecha en Amberes, bien en la edición de 1576 o la de 1583 .

El triunfo paulatino del español sobre el francés y el italiano es indicado en el poema de James Lea (que forma parte de los preliminares

\footnotetext{
1 Idem, f. Aiij v.

2 D. ALoNso, Una distinción temprana de $B$ y $D$ fricativas, en $R F E$ XVIII, I93I, p. I7; L. CARDIM, Gramaticas Anglo-castelhanas e Castellano-anglicas. Cointbra, I931; C. B. BoURI,AND, art. cit., pp. 287·288.

8 STEP'Ney, o. c., f. Aij v. de la Epistola Dedicatoria.

- "toward the furtherance of all those which are / desirous to learne the said tongue within this our Realme of England".
} 
de la obra de Percyvall): "ahora la lengua de Castilla irrumpe con fuerza (ignoro cómo), y, aunque último en llegar busca idéntico trato que los primeros" ${ }^{1}$.

Si Stepney dota a los ingleses de un instrumento práctico para aprender español, aunque tosco y poco idiomático, John Minsheu en 1599 representa, con sus Pleasant and Delightfull Dialogues in Spanish and English, el verdadero creador y conocedor de la riqueza y matizaciones del castellano; estos Diálogos - que constituyen su aportación original, ya que las dos primeras partes son reediciones aumentadas y corregidas de la obra de Percyvall - todavía hoy se leen con verdadera delicia y tuvieron amplia difusión en Europa merced a las traducciones de Oudin en el siglo XVII ${ }^{2}$.

En diez años Inglaterra posee ya un instrumento idóneo; los hitos históricos que jalonan esta carrera ascendente podrían ser: 1588 , desastre de la Invencible, pero clara inclinación de la balanza hacia España en Francia; 159r, desastre armado de Inglaterra en las Azores y la entrada de A. de Farnesio en París; r598, la llamada generación pacifista (Jacobo I adopta el lema beati pacifici). A estas fechas corresponde la aparición de las obras de A. de Corro (1590), Stepney y Percyvall (159I) y Minsheu (1599, al año siguiente de la muerte de Felipe II y la firma de la paz de Vervins que acaba con las guerras religiosas).

\section{B) Intercambio espiritual y social; necesidades de saber y alcanzar honores}

He intentado poner de manifiesto que la posesión de otra $\mathfrak{u}$ otras lenguas en circulos cortesanos, hunde sus raíces en un fenómeno de propagación de la actitud de los hombres doctos; actitud no interesada, es decir no politizada, sino basada en la necesidad de conocer y comunicarse; en una palabra: enriquecerse espiritualmente (actitud receptiva) y hacer a otros partícipes de este enriquecimiento (actitud proyectiva). En esta doble actitud se apoyaba Villalón para justificar su Gramática (1588): "porque la pudiessen todas las naçiones aprender: pues el bien es mayor cuanto mas es comunicado: por estas razones intente subje-

1 "Yet now at length (I know not how) steps Castile language in, / And craues for credit with the first, though latest she begin". El poema completo en C. B. BOURI,AND, art. cit., p. 287, n. 2.

- Cf. M. Gautigr [= Foulché-Delbosc], RHi. XI,V, 19I9, pp. 75-I45. 
tar la arte con reglas y leyes' ${ }^{1}$. También ha quedado apuntado, con todas las salvedades necesarias, que la preferencia por una u otra lengua está sometida al flujo y reflujo de las cambiantes situaciones polfticas. Veamos otras motivaciones aducidas.

Cuando nos enfrentamos con estos manuales de español - no ciertamente todos-observamos dos hechos sicológicos íntimamente ligados. Suelen los preliminares incluir una dedicatoria a personaje ilustre al que se califica de aficionado a las humanidades en general o al conocimiento de lenguas extranjeras; es un modo de prestigiar la obra y ponerla a salvo de críticas y ataques; pero al mismo tiempo sirve para incitar y estimular el deseo imitativo del público. $Y$ suelen también añadir una epístola al lector encareciendo los beneficios derivados para el espíritu y la consecuencia práctica de ellos: alcanzar bonores.

Así Stepney califica a sir Robert Cecil -el antecesor de Richard Cecil, valido de Jacobo I- de muy aficionado, como otros ilustres caballeros, a la lengua castellana "también como a las otras lenguas ${ }^{2}$. Christoval de las Casas dedica su Vocabulario a D. Antonio de Guzmán, Marqués de Ayamonte y Señor de las Villas de I,epe y Redondela, señalando: "vna cosa principal restaua... en este libro, que era vn fauor, y autoridad, que le hiziesse admitir bien, y respectar entre la gente: quise offrescerlo... a VS. Cuyo... entendimiento, virtudes, y ánimogeneroso... como por la afición y humanidad con que admite, y trata las cosas de letras, etc.1 ${ }^{8}$. A veces no hay dedicatoria expresa a personajes ilustres, sino que se resalta la consideración que el libro merece a las personas doctas; y asi Gravio (I556) [Al muy curioso lector. Francisco de Villalobos]: "Tanta es la vtilidad qu'en este libro se descriue (Curioso Lector), tanto es su vso, y exercicio... que su magnitud o grandeza de los hombres doctos es tenida por buena sin comparación"s. Como se ve, se sigue el mismo procedimiento utilizado en la literatura creativa $\mathrm{y}$, al igual que en esta, también en las Gramáticas los plagios son frecuentes; ya se ha aludido al de Sotomayor tomando el prólogo de Meurier y adaptándolo.

1 Gramatica / Castellana. / Arte breue y compendiosa para saber / hablar y escreuir en la lengua Ca- / stellana congrua y de- / centernente. Por el Licenciado Villalon [escudo]. En Anvers. / En casa de Guillermo Simon, ala / enseña del Abestruz. / M.D.LVIII. / Congracia y Priuilegio. Edición facsimil y estudio de C. Garcia, Madrid, I97I, p. 8.

O. cit., f. Aij v. Epistola Dedicatoria.

\& F. A. V.

- Citado en Bourland, art. cit., p. 293. 
Las razones esgrimidas ante el lector giran con varias formulaciones en torno a los beneficios espirituales del intercambio de ideas o al estímulo de promoción que el conocimiento de las lenguas lleva consigo.

$\mathrm{Y}$ así, Francisco de Villalobos, 1556: "Quien pudo jamas tener amistas con hombre de diuersas naciones con solo su lengua natural? Quien jamas hizo buen menage con solo una lengua ignorando las otras? Quien jamas gouerno bien la república con sola su lengua?» 1 .

E1 autor del Vocabulario de las dos lenguas Toscana y Castellana resume así la justificación de su obra: «paresciome tomar à cargo este trabajo... con que entendiendose esta lengua se puedad ambas comunicar, y gozarse tantos y tan buenos libros, como sabemos que ay en la Toscana... Fue assi muy importante, hazer este vocabulario el mas copioso que aöra pude, y hasta aquí se ha hecho: para que sirviesse, à poderse entender todo género de libros, en que ay mezcla tan varia, como vera bien quien lo leyere. $\mathrm{Y}$ con esto me paresce, que satisfazenos al desseo, que casi en general tienen todos los buenos espíritus de España, $\mathrm{Y}$ offrescemos tambien facil comodidad à la nasción Italiana, para que también puedan aprender nuestra lengua, y gozar assi mesmo de lo bueno que ay escripto...; agradesceran este trabajo, y recebiran no pequeño gusto de la comunicación de nuestros libros» ${ }^{2}$.

Jurito a encabezamientos neutros del tipo de Villalobos ( $A l$ muy curioso lector), o Av Bening Lecteur, de la Vtil, hallamos otros en la línea apuntada de incitación y estímulo, tales como «A los jóvenes deseosos de saber y honor" ${ }^{3}$.

Las reediciones (y concretamente las de Gravio), aparte de aludir al éxito y buena acogida, se justifican por la necesidad de no dejar incompleta la formación de los lectores; y es normal que siempre añadan algo (o cambien alguna lengua: 1558 francés, italiano, latín, español; I560 el flamenco sustituye al italiano), aunque el prólogo se mantiene en la misma línea de justificaciones: «me ha parecido faltar gran-

1 Idem, p. 296.

- Ch. de las Casas, o. cit., f. Ai y $\mathrm{A}_{2}$.

- El Prólogo de F. de Villalobos sólo aparece en la ed. de I550 de los Vocabularios Políglotas de B. Gravio. Cf. mi estudio de la Vtil y breve institution para aprender los principios y fundamentos de la lengua Hespañnla. Madrid, 1977, pp. XVI y XXIX-XXXI. La dedicatoria $A$ toutes ieunes gens qui desirent acquerre scauoir \& honeur aparece en otras ediciones del Vocabulario con ligeras modificaciones de redacción. ( $1551,155^{8}$ y 1560 ): 
demente a mi deber si no perseverara en mi intento de prestarle alguna ayuda y asistencia para acabar su iniciación” ${ }^{1}$.

\section{C) Valor intrinseco de la lengua}

Las cualidades intrínsecas del español han recibido por parte de gramáticos, historiadores y escritores un amplio tratamiento; basta recorrer las antologías de los Elogios de la lengua española o las Apologias de la lengua castellana en el Siglo de Oro, de Pastor, para tener pleno conocimiento del aprecio que merece nuestra lengua como instrumento artístico, no sólo en el sentido de su eficacia estética para lograr la comunicación de la belleza, sino también en un sentido técnico.

Es lógico que los escritores e historiadores insistan más en la dimensión primera señalada, en la que la lengua aparece como ergon, como obra acabada; y es también coherente que los gramáticos antepongan el aspecto técnico (su capacidad para ser reducida a arte) del cual se deduce como natural consecuencia su aptitud eminencial para decir todo - humano y divino- de forma bella.

Villalón en el Prohemio al Lector señala que: "todos cuantos hazen cueta de las lenguas y de su auctoridad dizen, que la perfeçcion y valor de la lengua se deue tomar y deduçir de poder ser reduçida a arte. $Y$ por esto dizen todos que las lenguas Hebrea, Griega y Latina son de mas perfeçcion” ${ }^{2}$.

El ser, pues, reducida a arte, a disciplina, a objeto de estudio según método, es para los gramáticos la piedra de toque que señala la perfección alcanzada por la lengua; como instrumento poseído, la lengua en si tiene virtualidades comunicativas ilimitadas; el arte las actualiza y de él depende el logro o la frustración de la perfección.

Interminables serfan las citas que podrían aducirse sobre esa abstracta perfección de la lengua española; casi se hacen tópicos los conceptos de elegancia, riqueza, fuerza, pasión o elocuencia; notas que con palabras de Villalón la hacen "muy acomodada a buen dezir» (p. Io).

1 wil m'a semble, que ie delfauldroie grandement à mon deuoir, si ie ne perseueroye à mon entreprinse, de leur donner quelque ayde \& assistence pour acheuer leur commencement, (Vocabvlario de quatro lingve, Francese, Latina, Italiana \& Spagnola. Vtilissimo a ciadascuno desideroso d'impararle isigue el título en latín, francés y español], f. Aij v. Ejemplar en la Biblioteca Nacional de Madrid, R. I7916).

O. cit., p. 5 . 
Este buen dezir no es más que la resolución lingiiística de una situación de modo penetrante, profundo, no trivial, en el que la comunicación logra eficazmente acercar la intimidad del pensamiento o del sentimiento de una forma valiosa.

De modo descriptivo, en 1599 James Lea alude a esta enorme fuerza del castellano frente al francés y al italiano: «se presenta - nos dice$\tan$ fastuosa y tan dulce; o mejor, más fastuosa: tan llena de preciosos proverbios y las más delicadas y particulares pullas; con graves consejos, amargos vituperios y dentelladas hirientes. Aunque florecen más las plumas eruditas en Italia y en Francia y en nuestra feliz Bretaña, donde hay tal acopio de eruditos, sin embargo el elenco en lengua española no cede terreno" ${ }^{1}$. Ignoro como habría calificado nuestra lengua si hubiese conocido los Diálogos de Minsheu (1599), en los que aletea permanentemente la ironía, el sarcasmo, la sal gruesa con quiebros que casi siempre sobrenadan y superan la baja chocarreria.

El otro aspecto de reducción a arte, a objeto de estudio según método, en los manuales para extranjeros no aparece, al menos de modo explícito, como cualificación de la perfección de la lengua. Sí se presenta en cambio, como facilidad para que el discente pueda adquirir la lengua; en otras palabras: el arte no sólo es manifestación de perfectividad, sino que además pedagógicamente puede ser reducido a elementos mínimos que permiten siquiera la iniciación segura en el estudio de la lengua; actitud que podramos compendiar diciendo upor la brevedad a lo esencialy.

$Y$ así Gravio (I555) nos habla de que "el presente libro te llevará por un bello y breve sendero de verdor, sin obstáculos de ramas, fango, espinas ni piedras, derecho al gran camino de la lengua castellanan ${ }^{2}$. Y como la brevedad de estos libritos actuará de acicate para una ulterior profundización, el mismo Gravio añade: «cuando veas la brevedad y utilidad del presente libro que te dará una fácil entrada al dicho conocimiento, no necesitarás ningún otro estímulon (p. 3).

\section{D) Contenido y Forma}

Esta simplificación metodológica de reducción a lo esencial, nos introduce en el tema de la justificación del contenido y presentación de los manuales.

1 Cf. C. B. Bourland, art. cit., p. 287.

2 Cf. mi estudio sobre la Vtil y Breve..., p. XXXV, n. 46 . 
El primer aspecto técnicamente implica el problema analítico de 1a Gramática, las partes que comprende. Las gramáticas renacentistas se encontrarán ante dos alternativas heredadas: la medieval de Alexander de Villa Dei (Ortografía, Etymología, Dyasintástica y Prosodia) y la clásica que responde a un criterio analítico de jerarquización de niveles, formulado así por Donato "Grammaticae partes quattor sunt, Littera, Syllaba, Dictio \& Oration ${ }^{1}$. Esta última alternativa será la seguida, en general, por los gramáticos; al estudio de cada uno de estos niveles corresponden respectivamente la Ortografía (Littera), Prosodia (Syllaba), Etimología (Dictio) y Sintaxis (Oratio). E1 tratamiento sistemático, tal como aparece en los cuatro primeros libros de la Gramática de Nebrija, no lo vamos a encontrar en los manuales para extranjeros que nos ocupan. Desde un punto de vista teórico, alguna vez se siente la necesidad de indicar cual sería el ideal del plan de estudio: upara bien i perfetamente hazerse (una Gramática) devia tratarse en cuatro maneras, dichas Ortografia, Etimologia, Sintaxe, i Prosodia” ${ }^{2}$.

Pero no debe olvidarse la finalidad práctica de estas obras para extranjeros. $\mathrm{Y}$ las justificaciones alegadas, aunque son pragmáticas, pudieran también defenderse teóricamente.

E1 Anónimo de Lovaina de 1559 indica que de la Ortografía y Etimologia "depende la conicion necessaria desta lengua" (p. 9) y concluirá su gramática resumiendo y justificando el plan inicial que eliminaba la Sintaxis y Prosodia dejadas ual uso común, de do se aprederan mejor i mas facilmente» (p. 9), con las siguientes palabras: "En el primer libro he enseñado la manera de cortar las palabras desta legua Vulgar [Ortografia]; en el segundo la variación de las palabras declinables [Etimologia]; las quales dos cosas son necessarias a todo buen principiante...; los que quizieren aprender bien i presto esta lengua, aprendan bien el primero, despues el segundo; tras esto dense a leer, escrivir, $i$ hablarla, que mui presto llegaran con ella al cabo" (p. 64).

Justamente este consejo práctico era cubierto por los Diálogos o Coloquios. Si como ha establecido Riemens, el Vocabulare de N. de Berlaimont es anterior a 1530 , y la primera versión de estos (I55I con el español incorporado) es anterior al primer manual gramatical para extranjeros (1555), podríamos conjeturar que para estos manualistas el conocimiento de una lengua es un hecho estrictamente empírico

1 Donati / de Octo Parti- / bvs Orationis / Libellvs... Lugdvni Apud Seb. Gryphum, 1543. Biblioteca Nacional de Madrid, $R$ 21841.

- Gramatica / dela Lengua Vulgar / de España..., p. 9, Lovaina, 1559, ed. facsimilar y estudio de R. de Balbin y A. Roldán, Madrid, rg66. 
que nada tiene que ver con el metalenguaje descriptivo. En otras palabras: la Sintaxis no es una parte de la Gramática, conclusión a la que llegaría el Brocense en 1587 con su Minerva (no en 1562 con sus Verae brevesque Institutiones): "Alij verum diuidunt Grammaticam in Litteram, Syllabam, Dictionem \& Orationem; siue quod idem est in orthographian, prosodian, etymologiam \& syntaxim. Sed oratio siue syntaxis est fini Grammaticae; ergo igitur non Pars illius" (p. 6). Puede, pues, conjeturarse que para los manualistas la Sintaxis es cuestión de práctica, cuyas reglas de gramaticalidad son hábitos de repetición. De ahí la presentación formal de los Coloquios y Diálogos: enfrentando las versiones de modo que línea a línea puedan cotejarse las oraciones. En esta misma línea práctica, los Coloquios ofrecerán al lector dos tipos de complementos. E1 primero: breves tratados de Prasodia y Ortografía, no exhaustivos, sino pensados según la lengua poseída por el discente y la que ha de aprender; se trata, pues, de describir las diferencias. Gravio ( 1558 ) afirma: "[hemos puesto] la Ortografia Francesa, la cual será muy útil a quienes deseen aprender a escribir dicha lengua. Hemos también impreso el arte y ciencia de escribir, leer y pronunciar la lengua española: por el cual se verá la diferencia de pronunciación entre la lengua Latina y Española" ${ }^{1}$. Este tener presente siempre la lengua nativa del discente explica, por ejemplo, que el Anónimo de I555 estudie sólo cinco diptongos cuando ya Nebrija había demostrado por combinatoria la existencia de doce.

En cuanto al segundo complemento de los Coloquios -el Vocabulario- dentro del aprendizaje es siempre posterior; el mundo referencial a que apunta el léxico no es en absoluto algo que pertenezca a la Gramática. Las dos citas que doy a continuación, de muy diversa procedencia y objetivo, mostrarán, sin embargo, la acertada visión que del vocabulario tienen los autores de manuales. La primera cita es del Brocense: «Mihi perfectus absolutusque Grammaticus est ille, qui in Ciceronis, vel Virgilij libris intelligit quae dictio sit nomen, quae verbum $\&$ caetera, quae ad solam Grammaticam spectant, etiam si sensus verborum non intelligat» ${ }^{2}$. La segunda cita es la justificación que da Gravio del valor relativo del vocabulario: «es menester cõsiderar por que lettras comiença el vocablo que buscais y despues buscarlo diligentemente. Halladas pues las diciones, las podreys ayuntar y poner por orden... Mas para hazer esto y ayuntar bien las diciones, es menester saber

1 Vocabvlario / de guatro lingve..., f. Aij v.

2 Minerva sive de Causis Latinae Linguae..., I587, p. 6. Ejemplar en la Biblioteca Nacional de Madiid. 
trasladar y formar los verbos por sus tiempos y personas en sus coniugaciones» ${ }^{1}$.

En la planificada labor de Gravio estas exigencias estaban cubiertas con la edición de las Gramáticas castellanas de I555 y la de I559, y en I555 la italiana de Acharisi Dacento con traducción francesa. Por el contrario otros reeditores de los Coloquios tuvieron que echar mano de Conjugaciones y Declinaciones ya publicadas, principalmente las de Meurier, para incluirlas en su obra; así ocurre con Girard de Saleson (Gantes, I568), etc.

\section{E) Motivaciones comerciales}

No es preciso insistir en la importancia que el factor económico juega en la vida de los pueblos; decisiones políticas o desencadenamiento de situaciones históricas están determinadas en muchos casos por actitudes económicas; sin que ello quiera decir que la interpretación económica de la historia sea la clave esencial, dada la complejidad de factores determinantes de ésta.

La primera gramática española conocida para extranjeros es la de 1555; si es el primer manual para aprender español, cronológicamente el francés se anticipó y colocó en los mercados ingleses la obra de Palsgrave, Eclaircissement de la langue Françoise en 1530, y posteriormente el French Littleton de Hollyband (I566), etc.

Sin embargo hay un hecho que conviene resaltar. Las ediciones de gramáticas españolas de los Países Bajos y en especial las de Gravio, están determinadas por el papel comercial preponderante que juega Amberes, íntimamente ligado a la etapa germano-flamenca de Carlos V (I544-1556) y muy especialmente a su residencia desde I553 en los Países Bajos. Es por estas fechas cuando el Emperador intuye una nueva concepción del Imperio -desgraciadamente irrealizable-: un imperio-potencia como en $155^{2}$, un imperio supranacional o territorial

\footnotetext{
1 Colloqvia Familiaria / Cum Dictionaric quatuor Linguarin..., Lovaina $\mathbf{I}_{5}$ 60, f. M r.

2 Cf. J. L. Comeirlas, o. cit., p. 28 r. Lespués de Mülhberg (1547), Carlos V barrunta la necesidad de transformar el estado supranacional investido tan sólo de la autoridad moral dimanante del hecho de la elección divina por medio de la unción papal, en un estado-potencia que por su poderio militar obligue a las otras naciones a aceptar el orden cristiano. La evolución de la idea imperial de Carlos V es, por otra parte, ampliamente conocida como para insistir en ella.
} 
no sólo europeo, sino mundial, atlántico: Esspaña como núcleo espiritual y humano, las Indias como soporte económico y los Países Bajos (desvinculados de su herencia germánica) como el gran centro comercial marítimo y financiero. Si añadimos que en $\mathrm{I}_{553}$ ha casado a su hijo Felipe con la católica María Tudor, se cierra el poderoso eje del soñado imperio atlántico: Sevilla (receptora del oro y plata de Indias), Valladolid (corte impulsora), Medina (primer mercado nacional y ruta de la lana hacia los Países Bajos), Amberes (corazón de la banca mundial) y Londres (el puerto de mayor actividad). Incluso Carlos $\mathrm{V}$ piensa dar libertad a los flamencos para traficar directamente con América ${ }^{1}$.

Este contexto justifica, en mi opinión, el distinto alcance de las ediciones flamencas respecto, por ejemplo, a las que se hacen en Inglaterra para aprender francés o italiano. Quizás no sea aventurado centrar la línea intencional divisoria entre el Vocabulare de N. Berlaimont y sus derivaciones en el factor comercial. El Vocabulare se publica en la etapa española del Emperador (I5I6-I529) o en la mediterránea (I530-I544), según consideremos la primera edición desaparecida (pero anterior a 1530, según Riemens) o la segunda de 1536. Si se tiene en cuenta el posible origen franco-flamenco del autor (como conjetura Verdeyen), las cualidades pedagógicas de este maestro de Amberes manifestadas - según Bourland-- por la disposición de la materia, viveza y realismo del diálogo, etc., no sería aventurado pensar que el pequeño librito de 84 págs. tenía como objetivo preciso lograr el entendimiento lingüístico entre esas dos amplias zonas en que se dividen los Países Bajos: al N. el país flamenco con sus $13.500 \mathrm{~km}^{2}$ y al S. el país valón francoparlante con sus $16.900 \mathrm{~km}^{2}$, la capital de Bruselas en la provincia de Brabante, bilingüe, pero la misma provincia dividida lingüisticamente (la parte septentrional flamenca y la meridional francesa). Por el contrario, las ed. derivadas del Vocabulare, y concretamente las de Gravio, ofrecen justificaciones que engloban el tráfico comercial y humano como razones para la publicación. $\mathbf{Y}$ estas razones están ausentes en el Vocabulare de Berlaimont.

No deja de ser sintomático que sea en la ed. de Gravio de I556, justamente cuando el Emperador proyecta dar libertad comercial a los flamencos con América, cuando aparece este tipo de justificaciones. Obsérvese la matización diferencial que se da entre la primera ed. (I55I) y la del 56 . En la primera se señala que el conocimiento de varias lenguas es muy importante en Flandes por las muchas naciones que se

1 Cf. J. I. COMELLAS, O. cit., p. 295. 
reúnen allí ya sea en la corte de Bruselas, en la Universidad de Lovaina o en la ciudad de Amberes ${ }^{1}$. En la ed. de I556: «no ay hombre en toda Francia, ni en Flandes, ni en Alemaña, ni en Inglaterra, ni en todas estas partes del septentrión, que no tenga grand necessidad de la cognicion de todas estas quatro lenguas qu'en este libro estan escritas, o sea mercader, o soldado, o hombre de palacio, o caminante et.» ${ }^{2}$. La referencia a las partes del septentrión (Dinamarca y Suecia) merece ser señalada: el paso del Sund era la ruta que abastecía de cereales a los Países Bajos.

\section{F) La Lengua al servicio del Imperio}

En este último apartado, en que las justificaciones son esencialmente políticas, me detendré someramente en tres aspectos:

r. Política interior.-E1 nombre de la lengua en su dualidad español/castellano, sobre el que existe suficiente bibliografía, pero que yo enfocaré aquí desde la perspectiva del editor.

2.0 La Lengua y el Emperador.-Este aspecto también será brevemente tocado porque la bibliografía sobre el desarrollo de la idea de Nebrija ("siempre la lengua fue compañera del Imperio" ${ }^{3}$ ) historia ampliamente el tema; me centraré por ello en la condición flamenco vs. español de Carlos V.

3. Afinidad lingüística español/latín.-Essgrimido como argumento explícito de la superioridad del castellano y consecuentemente lengua heredera de la misión romana de centro espiritual y, al servicio, pues, de la idea imperial de estado territorial.

1 ù̀ cause de diuerses nations, qui sont tant à la court de la Maiesté Impériale \& de son filz. Philippe d'Austrice, prince d'Espaigne, et de pays depardeça:, que à la tresfameuse Vniversité de Louuain, lá ou sont toutes nations de gens \& en Anuers marchans de tous pays". Cf. el texto completo del Prólogo de 155I ( $A$ toutes ieunes gens sfauoyr \& honneur desyderant?) cn R. VERDEVEN, Colloquia et Dictionariolum..., t. I, I926, p. XX, n. 2.

2 Cf. C. B. Bourtand, art. cit., pp. 293-294, donde se reproduce integro el prólogo que escribió F. de Villalobos para la ed. de 15.56 , que Gravio publicó con el título Dictionarium quatuor linguarum.

- Gramática Castellana, prólogo, p. 5 de la ed. de Galindo Romeo-Ortiz Muño\%, Madrid, 1946. 
I. ¿Españo1 o Caste11ano?

La Vtil y Breve institution fue publicada anónimanente por Gravio en 1555 ; la fecha es importante porque como ya he señalado coincide con los años de maduración del proyecto de un Imperio mundial, atlántico.

$¿$ Desde qué perspectivas enfocan editor y autor el nombre de la lengua? Para el editor siempre es lengua castellana (tres veces y una lenguaje castellano), de acuerdo con el uso dominante en la primera mitad del siglo XvI.

En cambio una sola vez aparece en el texto de la gramática el nombre castellano frente a español, lengua española; y ello por una decidida actitud del autor que toma partido contra la tesis tradicional. Si para Gravio (podría pensarse) el término lengua castellana es simplemente identificativo de una lengua que tuvo su origen en Castilla y por ello la expresión carece de connotaciones políticas, en cambio el anónimo autor enriquece el neologismo "lengua española» con tales connotacio- . nes que reflejan la tesitura recelosa de los no castellanos frente a una manipulación ambiciosa del nombre como cosa que conviene propia y peculiarmente a Castilla.

Sin embargo, no creo que en la mente de Gravio el vocablo lengua castellana fuese totalmente neutro respecto a la designación de una variedad lingüística; por el contrario, es una elección consciente, que supone una actitud valorativa del castellano frente a las otras hablas peninsulares; acaso sea ya sintomático el hecho de que en las ediciones políglotas de $\mathrm{I}_{558}$ y 1560 hable siempre de los correctores como castellanos nativos expertos en su lengua; pero, justamente en la primera edición del Vocabulario (I55I) afirma explícitamente la superioridad del castellano: "La Langue Castiliane est translaté par deux hommes sçauants, \& en leur langue maternelle tresloquents, $\&$ bien parlants: laquelle langue est la plus excellente de toute Espaigne» ${ }^{1}$.

1 Cf. n. I, pág. 19, W. BAHNER, Lingütstica Española del Siglo de Oro. Madrid, 1966, p. 164, ha visto, en mi opinión, con claridad el problema que nos ocupa. Considerar, por ejemplo, el italiano como latin corrompido y el castellano como lengua enriquecida por el latín (Velasco [Prete Jacopín]), permite conjeturar que en estas afirmaciones subyace la teoria del castellano primitivo, fundamentada históricamente en el papel predominante de Castilla "cabeza de España». 
2. La Lengua y el Emperador

Carlos V nace en Gante, que es de habla flamenca; el Emperador es bilingüe: habla francés y flamenco; ignora el español: el procurador por Burgos, Zumel, en el memorial de agravios de las Cortes de Valladolid (I5I8), pide, entre otras cosas, que Carlos V aprenda castellano; tampoco hablaba alemán, según el sentir general de los historiadores, aunque sobre el conocimiento del alemán he aducido algún testimonio contemporáneo que contradice esta opinión negativa (sin olvidar que desde I520-22 y I540 a I553 reside en Alemania).

Nos encontramos, pues, ante dos hechos: un nacimiento extranjero y por un azar histórico Rey de España. Podríamos sintetizar esta situación en una antinomia: naturaleza vs. nacionalidad.

Hasta su regreso a España en 1522 su nacionalidad de hecho y de corazón sigue siendo flamenco-borgoñona (consejeros, regente, etc.). A partir de esa fecha su hispanización es creciente: ha aprendido español (el documento de perđón a los comuneros, por primera vez, está en castellano), se casa con una princesa hispano-portuguesa (Isabel), cosmopolitiza los consejeros regios (borgoñones, italianos, alemanes, holandeses y españoles: Cobos, Guevara, Valdés, etc.).

Esa dualidad naturaleza/nacionalidad es esgrimida, desde el lado que interese para incitar al estudio del español, en algunos prohemios de gramáticas publicadas en Amberes; me referiré concretamente al Anónimo de 1555 y la Gramática de Villalón ( 1558 ).

Gravio indica que la utilidad de estudiar español radica, entre otras razones, en "que nuestro Principe natural nacio Rey de las Españas» (p. 3). La frase pudiera pasar inadvertida, pero creo que debe ponerse en relación con la opinión, aceptada por los historiadores, referente a la actitud de Carlos V respecto a su Imperio. Carlos $\mathrm{V}$ actúa ante todo como Emperador uno como Rey privativo de un pais al que se contrapusieran de algun modo el resto de sus dominios...; una cosa es hacer de España el centro del Imperio y otra cosa muy distinta ser ante todo rey de España" ${ }^{1}$.

La afirmación de Gravio hecha en un momento en que las decisiones que afectan a la política europea se toman en los Países Bajos, debe, en este contexto, entenderse en mi opinión de la siguiente manera: el pie de igualdad de todos los estados imperiales, $y$ en este soñado estado supranacional, España es una herencia de un príncipe que antes que nada es flamenco.

1 Cf. J. I. Comerisas, o. cit.; I, p. 240: 
Quizás pudiera parecer forzada esta interpretación; pero el siguiente texto de Villalón me inclina a ella. Dice Villalón: «forçome... a esta empresa ver el comun de todas las gentes inclinadas a esta dichosa lengua: y que les aplaze mucho y se apreçian de hablar en ella. El Flamenco, el Italiano, Ingles, Frances. Y aun en Alemania se huelgan de 1a hablar: aunque se presume que sea alguna parte de causa ver que el nuestro Emperador Carlos se preçia de español natural. Que ansi vimos, que al tiempo que su magestad vençio la batalla a Lansgraue y al Duque de Saxonia junto al rio Albis, vinieron todas sus Señorias y principados de Alemania a se le subjetar y obedecer: y a demãdar le perdõ. $Y$ todos le hablaũa en español:: aunque pareçe que era algo por le complazer» (p. 9-Io).

Justamente esta contraposición Principe natural/Español natural denota las dos actitudes; en el primer caso el conocimiento del castellano es necesario porque España forma parte de un estado que por naturaleza recae en un flamenco; en el segundo texto es la nacionalidad española, de la que se precia el Emperador, la que justifica la aquiescencia y beneplácito de sus súbditos por aprender su lengua.

\section{Afinidad lingǘstica Españo1/Latín}

Si se quiere tener una visión coherente de la cuestión de la lengua en el siglo Xvi es preciso no perder de vista - y buscar sus conexionestres aspectos fundamentales: el origen del lenguaje, la conciencia lingǘstica y la conciencia política; este último factor se presenta como causa explicativa de los dos anteriores y justifica, en gran medida, situaciones teóricas que pueden parecer a veces descabelladas lucubraciones sin contacto con la realidad, o celotipias de escuelas de carácter provinciano. En nuestro caso y desde el siglo XIII, por ejemplo, despertar una conciencia lingüistica unitaria era un hecho necesario que hundía sus raices en una coyuntura política; sin las conquistas de Fernando III, Alfonso $\mathrm{X}$ no se habría encontrado con la insoslayable obligación de buscar una base común que aglutinara dispersos territorios vitalmente diferentes; sólo en una lengua común -y el hecho ha sido certeramente expuesto por A. Castro ${ }^{1}$ - cabría buscar la unidad para lo que de hecho no era una entidad estructural sino un simple conglomerado; concebir lo castellano como un no querer ser ya latino, en frase feliz de A. Castro,

1 A. Castro, España en su Historia. Buenos Aires, 1948, pp. 478 y ss. 
es intentar interesar e incorporar a un proyecto político común (imperio peninsular y con perspectivas de europeo) a una casta a la que repugna vitalmente, religiosamente la lengua latina (los judíos). La politica lingüística sirve a la política de cancillería ${ }^{2}$.

Pero la conciencia lingüística se debate entre dos actitudes. Por una parte, el peso de una tradición cultural greco-latina, única a la que Santillana engloba en el estilo sublime, casi condena la propia lengua a un compartimiento cerrado apto en su esfera, pero sin las virtualidades expresivas para saltar del estilo mediocre al tratamiento de temas elevados $^{2}$. Y por otra parte -Mena- aun reconociendo la humildad, la rudeza del romance, movido por motivos patrióticos ${ }^{3}$, lejos de desistir del empeño de hacer de su propia lengua un instrumento idóneo al mismo nivel que el latino, se empeñará en la grandiosa empresa de dotar a la naciente nacionalidad del compañero indispensable: la lengua romance ennoblecida que se esclarece y acrecienta desde el latín. Cuando la idea imperial de Carlos $\mathrm{V}$-a través de sus distintos proyectostrata de imponerse en Europa, será Mena para los poetas del XVI la autoridad clásica por excelencia 4.

Esta primitiva tosquedad del romance se depura en contacto continuado con el latín; ambas lenguas recorren unidas un mismo camino; la fidelidad al latín (ya desde Lucena) es la piedra de toque para la jerarquización de las lenguas vulgares.

Por ello quizá sea una visión simplista - e inexacta al menos en su origen- la calificación de ujuegos científicos» y "fantasías de todo género" que da Thomas ${ }^{5}$ a los escritos, en boga durante mucho tiempo, que establecen un intimo paralelismo entre el latín y una lengua ro-

1 No nos interesa en estos momentos insistir en el otro factor sobre el que se ba querido cimentar la unidad política: la unidad religiosa; la afirmación de M. Pelayo: si España perdiera su unidad religiosa volvería al cantonalismo de los arévacos, resume la actitud de la politica religiosa que se inicia por lo que a la Edad Moderna se refiere con los $\mathrm{RK} C \mathrm{CC}$.

2 No dejan de ser sintomáticas estas palabras que JUAN DE LUCENA, Libro de vida beata (145́3), pone en boca de Santillana dirigidas al obispo de Burgos Alfonso de Cartagena: "Nuestro romance, señor Obispo. Ajeno de moral philosophia lo pensaba: jamás crel poderlo acomodar en cosas tamañas" (A. PA7. y MELIÁ, Opúsculos literarios de los siglos XIV a XVI. Madrid, 1892, p. III.)

8 Cf. J. M. BlecuA, prólogo al Laberinto de la Fortuna, Clásicos Castellanos, p. LXVII.

- Cf. mi edición de la Vtil y Breve, pp. CXIII-CXIV.

- I. P. Thomas, Le Lyrisme et la Préciosite Cultiste en Espagne. Etude Historique et Analytique, Halle-Paris, 1909, p. 38. 
mance determinada. $\mathrm{Y}$ ello sin negar que el procedimiento pudiera devenir puramente artificioso y manierista, desmochado ya de sus más intimas actitudes nacionalistas o proyectivas. La teoría de la corrupción lingüística del latín, cuyo gran artífice es $\mathrm{B}$. de Aldrete -con manifestaciones muy anteriores -1 al pasar del plano estrictamente "científico" al plano político adquiere una nueva dimensión: el grado de corrupción no es el mismo en todos los casos, e introduce un principio valorativo a la hora de considerar las distintas lenguas. La dirección política europea deberá corresponder a la nación cuya lengua sea más fiel heredera del latín ${ }^{2}$.

Quizás sea ya tópica la afirmación de que las gramáticas romances siguen la falsilla de las gramáticas latinas; no niego en absoluto que desde la Gramática de Nebrija se calquen los patrones clásicos. Pero junto a la explicación de una carencia de tradición romance, no debe olvidarse que la cuestión de la lengua, como he señalado, va íntimamente ligada al factor histórico-político de la hegemonía de las nacionalidades. En la medida en que la lengua sea más fiel al latín podrá recabar la hegemonía espiritual, directiva, aglutinante, que tuvo Roma; la nación de tal lengua será su heredera política. El tema ha sido objeto de diversos estudios ${ }^{3}$.

Aludiré muy brevemente - porque ya en otro momento la he analizado con gran amplitud-- a la Vtil $y$ breve Instittion. La finalidad de esta gramática (o al menos una de las ideas cardinales que la estructuran) era demostrar la conformidad de la lengua castellana con la latina: "Los Hespañoles assi como los Latinos scriben como hablan, y hablan como escriben"; "se escriue, y pronuncia como la Latina" y multitud de citas por todas partes de este mismo corte ${ }^{4}$. Al comienzo de

1 Cf. W. Bainner, o. cit., pp. $4^{1-73}$.

- La repercusión que en los movimientos literarios del XVI-XVII tiene la teorla de la corrupción fue vista por Thomas (o. cit.) y ha sido historiada en sus lineas fundamentales por Bahner (o. cit., pp. 147 y ss.).

- Cf. Bahner, o. cit., passim.

- Merece señalarse la reiterada atenuación que el Anónimo hace cuando constata la corrupción sufrida por el español (cf. mi estudio, pp. XXXII-XXXIII). Por un lado se inserta en la tesis del origen del castellano como degeneración del latín, pero mostrando, de cara a la confrontación con otras lenguas que fue menor que la sufrida por éstas; las gradaciones diversas con que encontramos esta atenuación de la corrupción alcanzará en \%apata la máxima cota ("el lenguaje toscano es latín corrupto, el nuestro es incorrupto latín"). Pero, por otro lado, pienso, que deben tenerse presente las tesis del castellano primitivo y la tesis vasquista para poder explicar de modo completo estas matizaciones de la doctrina del latín corrupto, que en Nebrija aparece sin ningún aditamento (no 
1a Gramática afirma: "trabajaron algunos hombres ingeniosos, y han salido con ello, que se escriuiessen muchas epistolas, o cartas, con vocablos Hespañoles, que fuessen Latinas, de tal manera que... los Latinos las tubiessen por latinas, los Hespañoles, por Hespañolas». Y justamente para probar este aserto, la Vtil se cierra con una epístola en que se exaltan las glorias españolas; si a lo largo de la Gramática no se señala sobre qué otra lengua tiene preeminencia el español, ahora en la Epístola aparece desvelado de forma apasionada: es sobre la lengua francesa sobre la que tiene el castellano derechos, diríamos, de primogenitura: manejar el patrimonio lingüístico latino como propio, situación vedada a la lengua francesa.

Nuestra Epístola, pues, se sitúa dentro del mismo espíritu, acertadamente diagnosticado por Erasmo Buceta, de las composiciones his-

es otra cosa la lengua castellana sino latín corrompido", o. cit., p. 27). Obviamente, frente a la teoria del castellano primitivo que prestigiaba la lengua con la aureola de una antiguiedad que se remontaba a Tubal, la tesis del castellano como latin corrupto ofrecia connotaciones peyorativas; es cierto que la tesis autóctona sólo se expone sistemáticamente en la obra de López Madera, Discursos de la certidumbre de las reliquias descubiertas en Granada desde el año 1588 hasta el de 1598, publicada en Granada en I 501 , por tanto con posterioridad a la aparición de la Vtil. Pero no debe olvidarse que en el Xv-xvi la tesis de Madera habia sido ya expuesta de pasada (Alonso de Madrigal y Florián de Ocampo); y sobre todo que la tesis vasquista fue corriente a mediados del xvI; el exacerbado nacionalismo de algunos de los vascófilos (Garibay, por ejemplo, en Amberes, 157r) con objeto de contraponer el papel único del vasco, acentúa las notas de degeneración del castellano e incluso para resaltar su origen no autóctono la llaman romance: "La lengua latina de los romanos perseveró en España constantissimamente hasta que en nuestros dias hablandola muy corruptamente, llamamos Romance, por auer sido lengua de Roma" (Garibay, Compendio historial de las chronicas y universal historia de todos los reynos de España. Anvers, 157 libro IV, cap. 4, p. 92). Piénsese, además, que la tesis de la corrupción despertó ante la utilización del nombre lengua castellana, recelos entre sus propios defensores (Anónimo de Lovaina, 1559: "es nombre ambicioso, i lleno de imbidia", p. 7) de origen no castellano, que contraponen diversas razones para ese exclusivismo; y una de estas razones por ejemplo en Viciana, 1574, es justamente que el castellano no solo es latín corrupto sino sobre todo procede de madre bastarda, «latín corrompido" que más se corrompió por arabismos y neologismos innecesarios. En esta situación, las atenuaciones que sobre la degeneración del latín dan origen al castellano son aplicables y se incardinan por tanto no sólo en el marco internacional (mayor excelencia sobre las otras lenguas), sino también como defensa en el ámbito nacional (frente a otras tesis sobre el origen del castellano, o desvalorizaciones regionalistas de este origen). La sombra peyorativa que conlleva la expresión 'latín corrupto'; quedaría eliminada por obra y gracia de Góngora, cuyas posibles relaciones con Aldrete -el máximo defensor de la doctrina latinistaha señalado Bahner, o. cit., p. 154, y que acaso merezca profuhdizarse. 
panolatinas: movimiento renacentista de afirmación de la lengua vulgar y aseveración de la preeminencia del Castellano sobre las otras lenguas romances. La historicidad de esta epístola fue afirmada por Buceta ${ }^{1}$; por mi parte, creo haber demostrado el carácter de ficción que tiene, analizando uno a uno los argumentos de Buceta, y aduciendo razones que estimo válidas y dignas de tenerse en cuenta.

Incluyo como Apéndice I esta Epístola, dado el interés que tiene como manifestación de la pugna entre el francés y el castellano; y, por 1a rareza bibliográfica de las Alabanzas de Viciana, ofrezco también la versión que de la Epístola dio en su obra el valenciano, según la edición del siglo xviri; el Apéndice III transcribe el Dialogus latino y español, obra de Fernán Pérez de la Oliva, incluido en el Ars Arithmetica de Martínez de Siliceo ${ }^{2}$.

La historia pormenorizada de la vieja polémica nacionalista, reflejada en estas manifestaciones lingüísticas, tanto en el frente italiano, como portugués y francés -en cada campo animado de un espíritu diferente-, queda todavía por hacer.

\section{A. Roldón PÉREZ}

\section{APENDICE I \\ EPISTOLA LATINA ET HISPANICA}

Vtil y Breve Institvtion para aprender los principios y fundamentos de la lengua Hespañola... Lovaina, 1555.

«Scribo \& supplico rogando te Francia des \& respondeas tales probationes, tractando de tua eloquentia, loquela \& excellentia, quales scribo de Hispania: comparando gentes, nationes \& prouincias: quales manifesto dictando epistolas puras, Latinas \& Hispanas. Hispania (antiquissima corona) perseuero (cessante memoria de contrario) duro, \& regno prouincia Christiana. Tu Francia principias à Moroueo, \& regnas continuando quasi mille annos christiana, praedicante sancto Remigio \& regnando Clodoueo. Et Hispania quasi ante quatercentum annos pracdicante sancto Iacobo Apostolo. Responde Francia, \& da \& propone contra nos tam grandes nationes, tam fertiles, tam fructuosas prouincias \& tantas, tales gentes, tam ingeniosas, tam scientificas, tam virtuosas, prudentes, iustas, modestas, liberales, graciosas, \& magnificas. Non monstras tu Francia tam grandes resistentias, \& tantas victorias contra Romanos. Ta Francia subiecta per Caesa-

1 Bafiner, o. cit., pp. 57 y 82 se hace eco de la opinión de Buceta.

- Cf. mi estudio de la Vtil, p. XCVI, n. I84. 
rem subito quasi ante tres annos. Et Hispania subiecta per Latones. Scipiones, Sertorios, Pompeos \& Caessares non ante ducentos annos. De perseuerentia \& constantia da testimonio Sagunto, Calaguria, Numancia, gentes feroces, constantes, \& magnificas. Praesenta tu Francia, \& da tales campos, montes, valles, tales bestias feras, \& domesticas, tantos \& tam excellentes caballos, tales vaccas, aues, carnes suauissimas, lanas preciosas, panes albissimos, tales plantas tam odoriferas, tales arbores tam fructiferas \& fertiles, fructuosas, in copia abundante \& copiosa, tantas mineras \& tam abundantes: tantas \& tam diuersas perfectiones. Prouincia manante vino clarissimo, oleo dulcissimo, auro purissimo, argento claro, plumbo, ferro, Stagno. Non cognosces tu Francia plantas, arbores, bestias \& perfectiones quales de Hispania maiores nos demonstramos. Et cognosco de Hispania infinitas quales tu Francia non cognosces. Si exaltas \& celebras principes \& Imperatores Romanos, demanda \& inquire de Bruto, de Fabio, de Adriano, de Honorio, de Theodosio, de Traiano inclyto \& glorioso Hispano. Si amas Poetas \& oratores, \& Historias veras, demanda de Seneca, de Quintiliano, de Lucano, de Marciale, de Trogo pompeo. Si honoras Astrologos, inquire de Alfraiano, de Albumazar, de Petragio, Alquibicio \& Abenazara, \& de grandi Alfonso. Si medicos, phisicos \& Philosophos, roga de Auicenua. Abenruy, Algabar, Alfrabio. Si canonizas \& sanctificas theologos, inquire de Alfonso sancto, Isidoro, Ireandro, \& Fulgentio, \& de diuino \& sanctissimo Laurentio, \& Vincentio. Si demandas eloquẽtia tam propinqua Latina, Responde dictando, \& compone libros, chartas tam Latinas \& vulgares contra vnas Hispanas \& Latinas tales." (f. Hvj\}, r. $\mathbf{y}$ v.).

\section{APENDICE II}

Alabanzas / de las Lenguas / Hebrea, Griega, Latina, / Castellana / Y Valenciana, / copiladas por / Martin de Viciana. / Y consagradas / al Ilustre Senado / de la Ynclita, y Coronada / Ciudad de Valencia. / Con licencia. / En Valencia: Por Salvador Fauli, Mercader / de Libros, junto al Colegio del Señor Patriarca, / donde se hallardn, Año 1765. B. Nacional, Madrid, R/26818.

"Beatissime ac Sancte Pater, / Legatus ab Hispania ad pedes vestre Sancti / tatis se prostat, \& dicit:

Si tu Francia Christianissima, Hispania, antiquissima, \& Catholica decorata a Summo Pontifice Romano Papa Innocentio Octavo, Et rogando te Francia scribas tales probationes, tractando de tua eloquentia, \& excellentia: tantas quantas, \& quales scribo de Hispania: comparando gentes, Nasciones, \& Provincias, quales manifesto dictando, \& continuando unas cartas puras latinas, \& Hispannas. Hispania antiquissima, \& coronada de corona regia, persevero, duro, \& regno cessante memoria de contrario. Et fuit Christiana ante tu Francia. Principias tu Francia à Clodoveo, \& regnas continuando casi mille annos Christiana: predicante Sancto Remigio, \& regnante Clodoveo. Et Hispania ante tu quasi quadringentos annos, predicante Sancto Jacobo Apostolo. Responde tu Francia, da, \& propone contrarias allegationes: \& proba tam grandes Nasciones, tam fertiles, \& tam fructiferas Provincias, tales gentes, tam ingenioses, tam scientificas, virtuosas, prudentes, justas, modestas, liberales, graciosas, \& magnificas. Non mostras tu Francia tam grandes resistencias, \& victorias contra Romanos, 
\& Carthaginenses. Tu Francia subjecta tota per Cesarem subito quasi ante tres annos: \& Hispania subjecta per Cathones, Scipiones, Sertorios, Pompeos, \& Cesares, non ante ducentos annos. De perseverancia, \& constancia do pro testimonio Saguntinos, Calagurritanos, Contestaneos, Edetaneos, Celtiberos, Illergetes, \& Numantinos, gentes feroces, constantes, \& magnificas. Presenta tu Francia, \& da tales campos, montes, valles: tales bestias feras, \& domesticas: tales \& tam excellentes cavallos, vaccas, aves, carnes, lanas, panes, \& huvas: tales plantas, tam odoriferas, \& medecinales: tales arbores, tam diversas, \& tam fructuosas: tantos mineros, \& diversos minerales: tantas salinas, \& tam grandes \& abundantes: \& tantas \& tam diversas perfecciones, \& Provincias manantes vino odorifero, oleo electo, auro purissimo, argento, ferro, plumbo, \& stagno. Non cognosces tu Francia plantas, arbores, bestias quadrupedes, \& perfecciones quales de Hispania nos majores demostramos: \& de Hispania cognosco infinitas, quales tu Francia non cognosces. Si exaltas, \& celebras Principes, \& Imperatores Romanos, demanda \& inquire de Viriato, \& de Adriano, Honorio, Theodosio, \& de Trajano, iriclyto \& glorioso Hispano. Si inquires Papas, monstro te de Damaso, de Calixto, \& de Alexandro Sanctissimo, \& ante nos presente, nativo de Valencia, Provincia excellentissima \& graciosa. Si amas poetas, \& Horatores, \& Historiografos, demanda de Seneca, Quintiliano, Lucano, Marciale, Trogo Pompeo, Plutarco, \& Mena. Si honoras astrologos, inquire de Alfagano, Albumazar, Alguibicio, Abenazara, \& Alphonso. Si Medicos, \& Philosophos, demanda de Avicena, Avenruiz, Algacel, \& Arnaldo de Vilanova. Si canonistas, \& Sanctos Theologos, inquire de Horosio, Prudencio, Ilephonso, Isidro, Leandro, Fulgencio, Dominico, \& Vincencio de Valencia. Si demandas de Grammatica, inquire de Anthonio de Nebrissa. Si de eloquentia, tam propinqua, \& propria latina, Hispania tota plena. Responde, \& compone tu Francia unas Orationes tam latinas, \& vulgares contra Hispannas, \& Latinas tales per nos ante publicadas in publico Sacro Consistorio Romano" (pp. 20-23).

\section{APENDICE III}

Ars Arithmetica Ioannis Martini Silicei: in Theoricen \& Praxim scissa: omni hominum conditioni perquam vtilis \& necessaria [escudo]. Venales habentur apud bibliopolam Hedmundum in vico sancti Iacobi in intersignio lune crescentis. Biblioteca Nacional, Madrid, R/24288.

«Siliceus. O quam profundas imaginationes apprehendo considerando quanto praecio tu nobilissima Arithmetica vales: quae personas infimas magnifica mente coronas. Tu subtiles contemplationes reuelas obscuros errores clarificando. Tu ingeniosas conclusiones monstrando pomposa mente triumphas. Quando tam altas recreationes cognosco culpo te misera ignorantia: tenebrosa insipientia: quae falsas vias procuras. O tu floridissima Arithmetica quae mortales fines pensando perpetuos honores procuras. Tu de vltima memoria me salua. Tu de mala fama me conserua.

Arithmetica. Si contra tam impetuosas acclamationes proterua resisto iusta mente me culpas. Voluntaria te amo notando quantas gratias: quales perfectiones: quam concordes doctrinas sustentas. 
Siliceus. Tu sola vna dignissima Arithmetica de euidente doctrina me adornas altissimas conclusiones manifestando: si tu ante odiosas intentiones / ante venenosos animos / ante inuidiosas murmurationes / de discordia me saluas: excellentissimos fauores sustentos.

Arithmetica. de sola prudentia tu curas discretas personas imitando.

Siliceus. de sola scandalosa discordia me fatigo: quando apprehendo diuisiones inclinationes diuersas / opiniones contrarias / prosperas fortunas contra miserias / constantes animos contra malas fortunas / duras persecutiones contra animos constantes / contra duras persecutiones defensiones fortissimas / contra fortissimas defensiones tentationes cautelosas / contra cautelosas tentationes honestos animos / contra animos honestos inuidias / persecutiones discordias / illusiones / cautelas / fallacias / malacias / murmurationes. Quae respondes tu altissima Arithmetica contra tantas diabolicas compositiones.

Arithmetica. Si temporales possessiones amas: perpetuas passiones procuras. Si ambitiones humanas: caducas glorias: si scientificas intellectiones: memorias immortales: aeternas recordationes: gloriosos fines spera. Si de mundano beneficio te priuas de infortunio te excusas / priuando te de dominio de captiua obedientia te saluas: priuando te de patrimonio cessas de anxioso seruitio.

Siliceus. si tu arithmetica de honesta fama me dotas tu sola altissima mente me amas.

Arithmetica amo te: amo siliceanas inclinationes Clara mente cognosco: o praestantissima Fama quantos philosophos exaltas quantos defunctos viuificas. Tu audaces animos incitas victorias altissimas causando: inuidias tu refrenas: falsas accusationes castigas causando altos honores ingeniosos animos recompensas tuque curiosa exaltando me de tanta gloria me augmentas: si me amas de solo Siliceo procura tu de eloquentia copiosa de honesta elegantia te arma: tu Siliceanas doctrinas praedicando profundas imaginationes reuela. Si tu amantissima fama de Siliceo procuras dulcissima mente te amo.

Fama. tantas perfectiones de siliceo cognosco quantas tu declaras disertissima arithmetica tu honores siliceanos spera. procedo Siliceanas imaginationes cantando.t 